
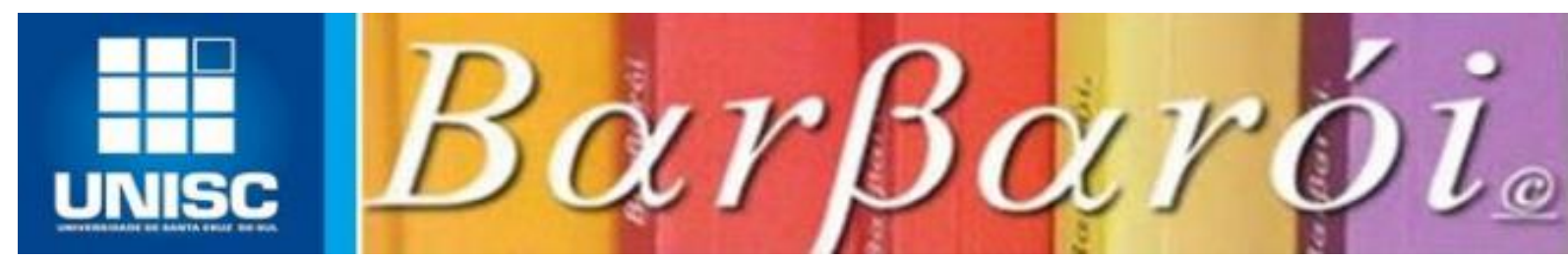

\title{
SLOTERDIJK E A DOMESTICAÇÃO PÓS-HUMANISTA EM HEIDEGGER
}

DOI: http://dx.doi.org/10.17058/barbaroi.v2i52.9982

\author{
José Roberto Carvalho da Silva \\ Universidade Federal do Maranhão - UFMA - Brasil \\ Wellington Lima Amorim \\ Universidade Federal do Piauí - UFPI - Brasil
}

\section{RESUMO}

Sloterdijk, em Regras para o parque humano, realiza uma resposta à carta de Heidegger sobre o Humanismo, demonstrando como este somente viu uma face do processo, a questão do esquecimento do ser, deixando impensado o seu caráter propriamente domesticador. Este caráter já havia sido pensado por Nietzsche. Porém, Heidegger, ao compreender o Humanismo como metafísica do esquecimento do ser e colocar Nietzsche como o último dos metafísicos, deu pouca atenção para o problema. Contudo, a partir de Sloterdijk e de sua leitura nietzscheana, o presente artigo tem por objetivo compreender como Heidegger supera o Humanismo, mas não sua domesticação, inaugurando a possibilidade da domesticação pós-humanista, onde não é mais o homem que domestica o homem, mas a própria casa do ser.

Palavras-chave: Humanismo, domesticação, Heidegger.

\section{INTRODUÇÃO}

Este artigo busca, não uma crítica, mas desvelar o lado impensado por Heidegger no que diz respeito à questão do Humanismo. Segundo Sloterdijk, Heidegger, ao concebê-lo como história da metafísica e do esquecimento do ser, esqueceu-se de sua outra face, antes identificada por Nietzsche, a questão da domesticação do humano. Desse modo, a partir de Sloterdijk e de sua leitura nietzscheana, apresenta-se um Heidegger que não somente esqueceu a domesticação da metafísica humanista, como também lhe inaugurou esta outra possibilidade para além do Humanismo: a do homem domesticado pela casa do ser e não pelo próprio Homem. Ao criticar a noção de verdade lógica (correspondência entre coisa e anunciado), Heidegger propõe a verdade originária (alétheia), esclarecendo o seu movimento de velamento e desvelamento, ou esquecimento e lembrança, do ser. Assim, tal verdade nunca é apropriada plenamente, mas apenas uma face que ela mesma revela ao Dasein. Em seu nome, Heidegger realiza a superação do Humanismo, colocando-a acima da noção de sujeito e como lugar de escuta do ser. 
Porém, para concordar com o próprio Heidegger, não se pode dizer que ele desvelou toda a verdade sobre o Humanismo, pois, como será visualizado, existe outra face, na qual ele mesmo não laçou a menor luz. Segundo Sloterdijk, essa face esquecida por Heidegger é o caráter propriamente domesticador do Humanismo. Em verdade, Sloterdijk afirma que Heidegger não somente deixou intocado o problema da domesticação, como também inaugurou a possibilidade de uma domesticação pós-humanista, agora pela casa do ser. Sloterdijk, decerto, não retira esta questão da domesticação do nada; antes se refere à Nietzsche, que a compreendeu como produção de animais capazes de fazer promessas. A novidade de Sloterdijk é que ele compreende a transformação disto em Humanismo como um processo que só existiu em virtude da cultura midiática dos livros. Assim, ele faz uma releitura de Nietzsche para denunciar a tendência domesticadora de Heidegger, que, embora seja pós-humanista, recorre ao mesmo meio midiático do Humanismo, a saber, os livros.

A pertinência disso é salutar, principalmente porque Heidegger foi um crítico de Nietzsche, acusou-o de o último dos metafísicos, o platônico invertido, e doravante, através de uma leitura sloterdijkiana, o pensador da Floresta Negra é desvelado como o último dos domesticadores, pois não é mais o homem que domestica o homem, e sim a própria casa do ser. Assim, Heidegger se revela como o último domesticador justamente porque ele apresenta a última possiblidade de domesticação além do Humanismo. Porém, para Sloterdijk, mesmo essa possibilidade necessita dos mesmos meios de propagação do Humanismo ${ }^{1}$, a saber, os livros, com os quais o permanecer-se sentado e atento ao que diz o autor é o mesmo que domesticar-se. Além disso, no mundo dominado pelas novas mídias (TV, Internet), as quais realizam um papel desinibidor, o livro se tornou marginalizado e terminal, de modo que a tentativa de domesticação heideggeriana parece já nascer morta.

$\mathrm{O}$ artigo que segue dispõe de três referências com as quais se realizará o trabalho. O Regras para o parque humano de Sloterdijk é o texto chave, e em volta dele os demais se posicionam, com o objetivo de analisar como Heidegger supera o Humanismo, porém não o seu caráter domesticador. A Carta sobre o Humanismo de Heidegger é abordada para aprofundar o que Sloterdijk identifica como superação heideggeriana do Humanismo e do esquecimento do ser. A Genealogia da Moral e Assim falava Zaratustra são as obras base de Nietzsche para compreender o Humanismo como escola da domesticação, face impensada por Heidegger, fundamentando a leitura de Sloterdijk. Ainda no Regras, analisa-se como Sloterdijk compreende o fim do Humanismo

\footnotetext{
${ }^{1}$ Vale ressaltar que a Carta sobre o Humanismo, apesar de propor a superação do Humanismo, ainda dispõe dos mesmos meios de sua propagação, a saber, o livro.
} 
enquanto escola literária da domesticação com o surgimento das novas bases de coexistência humana, como a TV e a Internet.

\section{O HUMANISMO E SEU FIM}

Para Sloterdijk, a história da civilização é a história da "errância”. Este termo heideggeriano significa a trajetória do esquecimento do ser. Nosso autor, porém, busca evitar compreender a errância em sua negatividade em relação ao ser, mas faz uma fenomenologia dela mesma. Para tanto, Sloterdijk recorre a Nietzsche e admite que a história da errância, entendida como Humanismo, é a história da escola da domesticação. O que Heidegger chama de errância é para Sloterdijk o caminhar do homem em busca da domesticação de si mesmo.

A percepção de que a história da civilização consiste no refinamento da domesticação da espécie humana pode ser antes detectada em Nietzsche. A Genealogia da Moral pode ser caracterizada como um trabalho que busca a origem da domesticação como alto valor, travestida em ações não egoístas. Em Assim falou Zaratustra, por sua vez, podemos ver o diagnóstico da desvalorização dessa valoração em face do apequenamento do homem² moderno resultante da domesticação. Portanto, Sloterdijk, ao pensar o humanismo como escola da domesticação, toma como pressuposto as pesquisas nietzschianas:

Nietzsche, em sua desconfiança contra toda a cultura humanista, insiste em arejar o mistério da domesticação do gênero humano e quer nomear explicitamente os que até agora detêm o monopólio de criação - os padres e professores, que se apresentam como amigos dos homens -, e quer trazer à luz sua função oculta, desencadeando uma disputa inovadora, no âmbito da história mundial, entre os diferentes criadores e os diferentes projetos de criação. (SLOTERDIJK, 2000, p. 40-41)

Ao buscar pela origem da moral na Genealogia, Nietzsche descobre que em sua raiz reside um principio imoral. Valores ditos não egoístas não são, pois, simplesmente dados e desde sempre bons. A genealogia se remete a um período onde a não afirmação da força própria corresponde a algo ruim, ao escravo, ao fraco, ao incapaz. Bom é o que, como uma ave de rapina, afirma a sua vontade de poder e se autoavalia como “o capaz” ou “o bom”, não se responsabiliza pelos próprios atos, nem conhece a culpa, vivendo do sadio esquecimento. Para Nietzsche, a moral tal como conhecemos, nasceu como oposição a essa moral nobre, e por isso ela é a moral dos escravos e dos

\footnotetext{
${ }^{2} \mathrm{O}$ último homem de Nietzsche, cujos valores precisam ser superados pela transvaloração.
} 
ressentidos. Os sacerdotes ascéticos foram os seus porta-vozes. Ao se sentirem representados, os escravos elevou essa espécie de homem ao mais alto valor. Os sacerdotes ascéticos deram início a esse projeto da moral enquanto domesticação do homem: fazer daquele animal nobre e impulsivo um ser memorioso e cumpridor de promessas eram o seu objetivo. Para tanto, porém, não foram nada morais os seus procedimentos, que tinham por base a mnemotécnica.

Esta técnica de domesticação visou desde sempre imprimir a culpa e a incessante memória contra o esquecimento desinibido e autoafirmativo dos fortes, causando-lhes dor, má-consciência, adoecimento, enfraquecimento, por meio da crueldade. Embora imprimisse a culpa, o mesmo sacerdote ascético oferecia o seu remédio: os ideais ascéticos. Neste caso, os meios justificavam os fins da humanização. Portanto, para que as ações não egoístas pudessem ser vistas como valores superiores foi preciso um longo processo de domesticação do humano.

Querendo-se com ela exprimir a ideia de que um tal sistema de tratamento melhorou o homem, não discordo: apenas acrescento que, para mim, "melhorado" significa - o mesmo que "domesticado", "enfraquecido", "desencorajado", "refinado", "embrandecido", "emasculado" (ou seja, quase o mesmo que lesado...). (NIETZSCHE, 1998, p. 131)

Em Assim falou Zaratustra, Nietzsche traz a figura do último homem, que seria o produto final e moderno do projeto de domesticação. No contexto desse homem, os valores superiores que sustentavam a domesticação (e que ao mesmo tempo a encobriam com vestes sublimes) terminam por se desvalorizar. Desvela-se assim a face do niilismo moderno: a domesticação não precisa mais de Deus e de seus sacerdotes ascéticos para sustentar-se, afinal de contas os homens aprenderam a domesticar a si mesmos. Os últimos homens estão continuamente vigilantes em domesticar uns ao outros em nome do nada: desconfiam de tudo que tem pretensões superiores: “Ah! Aproxima-se o tempo, em que o homem não lançará mais a flecha de seu desejo acima dos homens, e em que as cordas de seu arco já não saberão mais vibrar.” (NIETSCHE, 2011, p. 26).

Assim, a primeira transvaloração, aquela realizada pela moral do escravo, encontra seu sucesso moderno no nada. Por isso, Nietzsche propõe uma nova transvaloração, capaz de tirar a vida do niilismo em que se encontra e devolvê-la à riqueza que lhe é própria. Para o filósofo, o último homem, produto de milênios de domesticação, precisa ser superado, superado por um caos que subsiste silencioso nas regiões subterrâneas da consciência domesticada: “Eu vos digo: é necessário ter um caos em si para poder dar à luz uma estrela bailarina. Eu vos digo: tendes ainda um caos dentro de vós" (NIETZSCHE, 2011, p. 27). 
Sloterdijk, porém, vai além de Nietzsche em um ponto: ele afirma que o Humanismo, enquanto escola da domesticação, foi um evento midiático e literário. Desde o inicio, o Humanismo foi uma comunicação por meios de "cartas" entre amigos anônimos e distantes. Estas "cartas", se quisermos saber, foram os livros, por isso a humanitas foi desde sempre uma consequência da alfabetização. Tais "cartas" mais longas poderiam falar de amor ou amizade. Contudo, o desejo que movia as suas trocas não se reduzia a mera comunicação; havia ainda o desejo de impelir aos outros esse amor. Para Sloterdijk, sem dúvida, a recepção das "cartas" mais decisivas foi aquela dos romanos em relação aos gregos. Sem a boa recepção dos romanos, o ocidente jamais teria conhecido qualquer coisa de Humanismo, muito menos obras que falariam de Platão ou Aristóteles em latim, alemão, francês, ou, em nosso caso, em português.

Nessa corrente de cartas, o elo mais importante foi sem dúvida a recepção da mensagem grega pelos romanos, pois só a recepção romana abriu o texto grego para o Império, tornando-o acessível, pelo menos indiretamente, após a queda da Roma ocidental, às culturas europeias posteriores. (SLOTERDIJK, 2000, p. 8)

O Humanismo foi um evento literário sim, mas como relacioná-lo com a domesticação? Que os livros estejam relacionados com a domesticação do homem é algo que precisa ser compreendido a partir da estreita relação entre mídias, enquanto bases da coexistência social, e os processos de inibição e desinibição das tendências bestializadoras do gênero humano. Para isso, é necessário que se remeta ao local de surgimento das humanitas, na Roma de Cícero, e visualizar desde lá as mídias características dos humanizados e do seu contrário. Em oposição aos humanizados leitores de clássicos e amigos distantes dos gregos, estava a plebe bestializada, entretida nos anfiteatros e excitada pelos sangrentos e cruéis espetáculos dos gladiadores:

Só se pode entender o humanismo antigo se o apreendermos também como uma tomada e partido em um conflito de mídias - isto é, como a resistência do livro contra o anfiteatro e como oposição da leitura filosófica humanizadora, provedora de paciência e criadora de consciência, contra as sensação e embriaguez desumanizadoras e impacientemente arrebatadoras dos estádios. (SLOTERDIJK, 2000, p. 18)

Portanto, somente visualizando esta oposição entre mídias bestializadoras e domesticadoras é que se pode situar o livro como mídia principal do processo de domesticação que se chama Humanismo. As letras, no final das contas, domesticam os ânimos e alimenta a alma, 
distinguido o homem substancialmente dos animais e tornando-o cada vez mais próximo de sua essência racional e benevolente. "O sentido dessa escolha de meios consiste em desabituar-se da própria bestialidade em potencial, e pôr distância entre si e a escalada desumanizadora dos urros do teatro." (SLOTERDIJK, 2000, p. 19). Se existiu uma época em que o Humanismo se tornou militante eficaz de sua própria causa, esta época foi a moderna: "De fato, de 1789 a 1945, os nacionais humanismos livrescos estiveram em seu ápice." (SLOTERDIJK, 2000, p. 12) Em pleno estado moderno burguês, a alfabetização se tornou um direito universal, bem como a leitura dos clássicos nacionais. Sem dúvida, nisso a escola exerceu um papel decisivo para disseminar a mídia literária e exercer através dela, além do conhecimento, a domesticação. A mídia literária, de fato, disseminou-se como nunca, principalmente em função do surgimento da imprensa. Neste contexto, o Humanismo alimentou idealismos e utopias.

O serviço militar obrigatório universal para jovens do sexo feminino e a leitura obrigatória universal dos clássicos para jovens de ambos os sexos caracterizam a época burguesa clássica, isto é, aquela era da humanidade armada e dedicada à leitura, para a qual os novos velhos conservadores de hoje olham nostálgicos e ao mesmo tempo impotentes, [...] (SLOTERDIJK, 2000, p. 12)

Contudo, após o surgimento da TV em 1945, algo começa a mudar, pois os livros, embora com boa parte da população alfabetizada, não parece mais se afirmar sobre as mídias concorrentes. Neste contexto, inicia-se a crise do Humanismo e o início do seu fim, que se consolida com a Internet. O projeto moderno de domesticação das tendências bestiais do gênero humano chega ao fim não porque não tenha tido representantes dispostos para sua conservação - na verdade são muitos os conservadores -, mas sim porque sua arma contra os processos de desumanização teve sempre como pressuposto o livro como mídia, enquanto que na sociedade industrial os dispositivos bestializadores já vão para muito além dos anfiteatros romanos, que assumiram hoje a onipresença dos meios de comunicação de massa ${ }^{3}$, contra os quais a cultura literária se encontra impotente em estado de subsistência marginal: "é apenas marginalmente que os meios literários, epistolares e humanistas servem às grandes sociedades modernas para a produção de suas sínteses políticas e culturais." (SLOTERDIJK, 2000, p. 14)

\footnotetext{
${ }^{3}$ Vale ressaltar o papel decisivo das mídias de massa para a propaganda totalitarista.
} 


\section{HEIDEGGER E A DOMESTICAÇÃO PÓS-HUMANISTA}

"O primeiro humanismo, o romano, e todos os tipos de humanismo que, desde então até o presente têm surgido, pressupõe como óbvia a "essência" mais universal do homem. O homem é tomado como animal rationale." (HEIDEGGER, 2005, p. 21) Ao efetuar sua crítica à tradição humanista, que definiu o homem como animal racional, Heidegger de nenhuma maneira pensou a humanização do homem em termos de domesticação, pois esteve apenas preocupado com a questão do esquecimento do ser. Desse modo, o Humanismo seria a tradição que retirou do homem a "consciência" de ser ele mesmo o pastor do ser, um privilegiado habitante de sua casa, e deu-lhe o fundamento metafísico de se reconhecer como o senhor do ente. Para Heidegger, seria necessário realizar a destruição dessa metafísica através de um pensamento pós-humanista que pensasse ou relembrasse o que existe para além das representações do sujeito. Para além do sujeito está a verdade do ser que se desvela no mundo enquanto linguagem, isto é, a casa do ser:

O homem, porém, não é apenas um ser vivo, pois, ao lado de outras faculdades, também possui a linguagem. Ao contrário, a linguagem é a casa do ser; nela morando, o homem ex-siste enquanto pertence à verdade do ser, protegendo-a. (HEIDEGGER, 2005, p. 38)

Embora Heidegger não tenha colocado o Humanismo em termos de domesticação e somente de sua Metafísica, isto não quer dizer que ele não tenha se preocupado, ainda que indiretamente ou de modo implícito, com esse fator. Para Sloterdijk, a evidência disso se encontra na critica de Heidegger à concepção de animal rationale, concepção que não somente desviaria o homem de sua tarefa de pastor do ser, mas o forçaria a compartilhar com os animais, em termos ontológicos, uma essência. Dessa forma, não somente o racional, mas também o animal, seria uma definição metafísica, que nada diria sobre o homem em seu aspecto fundamental. Para Heidegger, uma vez habitante da casa do ser, o homem representaria uma cisão ontológica com a animalitas, ultrapassando a mera diferença de gênero ou espécie. Desta forma, o Humanismo, ao definir o homem como animal racional, ainda não teria pensado suficientemente sobre a dignidade originária do homem. Heidegger se voltaria contra humanismo não porque este tenha sobrevalorizado a humanitas, mas porque não lhe atribuiu um valor suficientemente elevado. (SLOTERDIJK, 2000) Heidegger deixa nas entrelinhas que essa dignidade reside em não ter nenhum laço essencial com os animais; não adiantaria, portanto, acrescentar o espírito ao animal, ainda assim o homem não teria sido pensado em sua essência mesma: 
Pensa-se, em princípio, sempre o homo animalis, mesmo que anima seja posta como animus vive mens e mesmo que antes, mais tarde, sejam postos como sujeito, como pessoa, como espírito. Uma tal posição é o modo próprio da Metafísica. Mas com isto a essência do homem é minimizada e não é pensada na sua origem. (HEIDEGGER, 2005, p. 23)

Para Sloterdijk, se o compartilhamento ontológico entre homem e animal acarreta em uma minimização da essência do homem, então Heidegger nesse momento já ultrapassa a questão do ser e passa se envolver com juízos de valor acerca da animalitas. Exatamente aqui surge a orientação axiológica nietzschiana: por que afinal o valor animal minimizaria a essência do humano e não o contrário para Heidegger? Segundo Sloterdijk, essa pressuposição de Heidegger o levou “ $a$ observações histéricas, como declara, por exemplo, que aparentemente "é como se a essência do divino estivesse mais próximas de nós que a desconcertante essência dos seres vivos"." (SLOTERDIJK, 2000, 25). Em face dessas observações, desvela-se que as preocupações heidegerianas de superação do humanismo ainda não conseguem se desvencilhar da pedagogia humanista da domesticação do homem. Assim, a casa do ser domesticaria o homem de uma forma que nenhum humanismo até então conseguiu: os homens falham ao domesticarem a si mesmo, mas não o ser; os homens não são tão eficientes em convencer outros homens que eles são mais que meros animais, mas ao responder ao apelo do ser o homem descobre imediatamente a sua essência incompartilhável.

Ao estar à espreita da casa do ser, o homem permanece dócil ao seu apelo e à escuta do essencial; o apelo do ser para a docilidade supera todos os apelos ônticos possíveis, sejam eles da família, dos professores ou padres. O ser domestica o homem para respeitá-lo e não entificá-lo. O sucesso heideggeriano ao compreender o Humanismo em termos de esquecimento do ser não o fez superar a domesticação. Ao contrário, o pensamento pós-humanista, que Heidegger apresenta, realiza uma proposta de domesticação que vai muito além das propostas literárias do humanismo. Porém, não somente neste ponto Heidegger não se desprende da tradição, pode-se dizer que, assim como na humanitas, ele ainda considera os livros como mídias de propagação do pensar. Com tais considerações, vê-se que a superação do humanismo de Heidegger ainda é incompleta, pois com a tradição ele ainda compartilha a vontade de domesticar e a esperança nos livros. Ora, viu-se que esta tradição entrou em crise com o advento dos meios de comunicação de massa e de embrutecimento. Assim, o pós-humanismo heideggeriano chega ao fim junto com o humanismo, por compartilhar com ele as mesmas tendências. A proposta extraordinária de domesticação 
empreendida por Heidegger já nasce, desta maneira, morta, apenas destinada a amigos cada vez mais anônimos e solitários na sociedade industrial.

Para Sloterdijk, certas tendências do humanismo não podem ser superadas com o pensamento da casa do ser, pois, ao contrário de Heidegger, para ele o fato de o homem ter mundo não o diferencia ontologicamente dos animais. $\mathrm{O}$ fato de morar na casa do ser não impede aos homens de terem uma essência animal. Ao contrário, diz Sloterdijk, é necessário que se faça uma genealogia da casa do ser para compreender em que período da história e como a espécie humana chega para dentro do seu recinto ontológico. De uma maneira ainda mais radical, Sloterdijk analisa que o fato de estarmos na casa do ser pode ter suas bases em nossa constituição biológica de incompletude animal, já que nascemos prematuros e permanecemos neotênicos.

Ela narra como nos longos períodos da história pré-humana primitiva surgiu do mamífero vivíparo humano um gênero de criaturas de nascimento prematuro que se pudermos falar de forma tão paradoxal - saíram para seus ambientes com um excesso crescente de inacabamento animal. Aqui se consuma a revolução antropogenética - a ruptura do nascimento biológico, dando lugar ao ato de vir-aomundo. (SLOTERDIJK, 2000, p. 33-34)

Portanto, ao tentar manter o Dasein puro de toda antropologia e paleontologia, Heidegger não teria percebido que a casa do ser não é tão originária assim, já que ela veio a ser. Sloterdijk defende que a casa do ser veio a ser no interior do desenvolvimento entropogenético da espécie humana. Dessa forma, ele realiza uma genealogia da casa do ser, procurando por quem somos, retirando a questão do mistério que Heidegger nos deixou. Assim, se existe algo que devemos ao humanismo, é o fato de ele ter deixado explícito que somos de alguma maneira animais, apesar do acréscimo racional. E se devemos algo a Heidegger, é o fato ele ter meditado e proporcionado uma compreensão originária desse lugar em que nos encontramos enquanto animais domésticos.

De fato, nascemos desamparados e precisamos de um receptáculo imunológico que nos garanta a insistência na ex-sistência. A casa do ser é este receptáculo no qual não somos aí lançados, mas acolhidos, como diria Sloterdijk. Sendo a casa do ser este lugar, podemos compreender e definir os seres humanos como animais domésticos, que por sua vez domesticaram outros animais que passaram participar de sua casa, como o gado, o cão e o gato: “Com a domesticação do homem pela casa começa, ao mesmo tempo, a epopeia dos animais domésticos. Ligá-los às casas dos homens não envolve, porém, apenas domesticação, mas também adestramento e criação." (SLOTERDIJK, 2000, p. 36) Uma investigação antropológica e 
paleontológica da relação entre casa do ser e domesticação mereceria mais desenvolvimento aqui, mas isso não ocorrerá nesta oportunidade. O importante é que a presença de uma domesticação póshumanista em Heidegger foi assim demonstrada.

\section{CONSIDERAÇÕES FINAIS}

Observou-se, portanto, o desdobramento do projeto de domesticação do homem, agora, pela primeira vez, em uma face pós-humanista. Esta se apresentou com a compreensão da casa do ser como espaço que determina o modo de ser do homem, ao invés de ser ele mesmo elemento fundador de si, como um sujeito autossuficiente. Desde modo, Heidegger acreditou ter superado a metafísica do Humanismo, mas, como foi analisado, ele inaugura um pensamento que leva a tendência domesticadora do Humanismo às últimas consequências. Para Sloterdijk, Heidegger descobre o âmbito ontológico que fundamenta a própria possiblidade de domesticação enquanto tal, mesmo sem tornar isso explícito. É a casa do ser, portanto, que faz o homem ser o animal doméstico que é. Através dela, Heidegger descobriu uma possibilidade de docilização que nenhum Humanismo havia ainda pensado.

Em Heidegger não é mais o homem que deve domesticar o homem, mas sim o respeito pelo ser, este mistério que nos concedeu a possibilidade de ser no mundo. O ser, com o qual somente o homem possui uma relação originária de correspondência, determina a essência humana que lhe pastoreia. Sendo pastor do ser, o homem não pode ser definido como animal racional, tal definição ainda colocaria o homem abaixo de sua dignidade, pois com os animais ele não tem nenhuma diferença de gênero ou espécie, mas uma diferença ontológica. Ora, Sloterdijk observa que nessa necessidade de diferenciação ontológica entre homem e animal de Heidegger reside ainda a presença da necessidade da domesticação, afinal, quanto mais distante do animal, mas perto de si mesmo o homem está, mais humano ele é, mais dócil.

Viu-se que para Sloterdijk o Humanismo tem chegado ao fim com o advento dos meios de comunicação de massa, pois seu principal veículo de disseminação, o livro, foi marginalizado, por exemplo, pela TV e Internet, que seriam lugares da desinibição das pulsões bestializadoras do homem. Porém, o fim da cultura do livro não teria terminado somente com o projeto humanista, mas também teria terminado com a própria proposta heideggeriana de uma comunidade assentada na casa do ser, pois embora esta proposta seja pós-humanista, ela ainda necessita dos meios humanistas de comunicação. 
Portanto, o que resta ser colocado é como se poderá aproveitar essas descobertas, uma vez que não se pode evitar a domesticação com o pensamento pós-humanista por sermos nós mesmos animais domésticos. Uma saída é concebermos a domesticidade como uma condição da espécie humana na terra e pensar em caminhos pós-humanistas de efetivar isso. Este caminho, naturalmente, não será mais pelos livros, mas quem sabe pela arquitetura, ou, como o próprio Sloterdijk tem proposto, com os espaços de mimo pós-modernos. Desse modo, não se excluirá as ciências da natureza na investigação do nosso ser animal e nem a ontologia na meditação daquilo que nós participamos enquanto espécie no mundo.

\section{ABSTRACT}

Sloterdijk, in Rules for the human park, makes an answer to Heidegger's letter on Humanism, demonstrating how he only saw a face of the process, the question of the forgetfulness of the being, leaving unthinking its properly domesticating character. This character had already been thought by Nietzsche. However, Heidegger, by understanding Humanism as a metaphysics of the forgetting of being and putting Nietzsche as the last of the metaphysicians, paid little attention to the problem. However, from Sloterdijk and his Nietzschean reading, this article aims to understand how Heidegger overcomes Humanism, but not its domestication, inaugurating the possibility of posthumanist domestication, where it is no longer the man who domesticates man, But the very house of being.

Keywords: Humanism, domestication, Heidegger.

\section{REFERÊNCIAS}

HEIDEGGER, M. Carta sobre o Humanismo. Tradução de Rubens Eduardo Frias. São Paulo: Centauro, 2005.

NIETZSCHE, F. Assim falava Zaratustra. Tradução de Mário Ferreira dos Santos. 6.ed. Petrópolis, RJ: Vozes, 2011.

. Genealogia da Moral: uma polêmica. Tradução de Paulo Cézar de Souza. São Paulo: Companhia das Letras, 1998.

SLOTERDIJK, P. Regras para o parque humano: uma resposta à carta de Heidegger sobre o Humanismo. Tradução de José Oscar de Almeida Marques. São Paulo: Estação liberdade, 2000.

\section{Sobre os autores}

José Roberto Carvalho da Silva é graduado em Filosofia pela Universidade Federal do Maranhão (UFMA) e mestrando em Filosofia pela Universidade Federal do Piaui (UFPI). Endereço eletrônico: j.roberto-10@hotmail.com 
Wellington Lima Amorim é Doutor em Ciências Humanas pela Universidade Federal de Santa Catarina (UFSC), mestre em Filosofia pela Universidade do Vale do Rio dos Sinos (UNISINOS) e Graduado em Filosofia pela Universidade Federal do Rio de Janeiro (UFRJ). Endereço eletrônico: wellington.amorim@gmail.com 